\title{
A STUDY ON FUNDUS CHANGES IN PREGNANCY-INDUCED HYPERTENSION: A FOUR-YEAR OBSERVATION
}

\author{
Elluru Pandu Rangaiah ${ }^{1}$, Gangisetty Madhavi Latha ${ }^{2}$, Sandhya $K^{3}$, A Latha ${ }^{4}$, Meena Syed ${ }^{4}$. \\ ${ }^{1}$ Civil Surgeon Specialist Department of Ophthalmology, District Head Quarters Hospital (Government), Chittoor, Chittoor District, India. \\ ${ }^{2}$ Department of Ophthalmology District Head Quarters Hospital (Government), Chittoor, Chittoor District, India \\ ${ }^{3}$ Civil Surgeon Specialist Department of Obstetrics and Gynecology, District Head Quarters Hospital (Government), Chittoor, Chittoor District, India \\ ${ }^{4}$ Civil Assistant Surgeon, Department of Obstetrics and Gynecology, District Head Quarters Hospital (Government), Chittoor, Chittoor District, India
}

\begin{abstract}
Introduction: Hypertensive disorders make difficulties in 5-10\% of all pregnant women, forming the deadly triad of haemorrhage, heart disease, and maternal morbidity or mortality. The goal of this research is to identify retinal changes in pregnancy-induced hypertension and to identify the assocition between retinal changes and hypertension severity.
\end{abstract}

Methods: Data from 100 pregnant women admitted with pregnancy-induced hypertension (PIH) were collected retrospectively over the last four years. Vision, Anterior segment, and Fundus were evaluated.

Result: Fifty-four pregnant women suffered from mild preeclampsia, 40 pregnant with severe preeclampsia, and six pregnant with eclampsia with seizures. $24 \%$ of pregnant had hypertensive retinopathy. Grade 2, 3, and 4 retinopathy were observed in $22 \%, 6 \%$, and $2 \%$ of pregnant women. Two percent of pregnants had macular edema grade 4 retinopathy (macular edema occurred simultaneously with hypertensive retinopathy), and 3\% had central serous retinopathy were noticed. The fundus findings have a significant positive correlation with the severity of hypertension $(P<0.001)$. Arteriole narrowing was the most common fundus finding $(45.7 \%)$.

Conclusion: Overall, 54\% of pregnants were recorded with hypertensive retinopathy. A positive correlation was observed between fundus changes with the hypertension severity. This study emphasises the importance of routine fundus examination in hypertensive pregnant women. Retinal change during pregnancy is one of the indicator for deciding whether or not to terminate the pregnancy.

Keywords: pregnancy-induced hypertension, fundus examination, retinopathy.

Cite This Article: PANDU RANGAIAH, Elluru et al. A Study on Fundus changes in Pregnancy-induced hypertension: A Four-year Observation. International Journal of Retina, [S.I.], v. 4, n. 2, p. 162, sep. 2021. ISSN 2614-8536. Available at: <https://www.ijretina.com/index.php/ijretina/article/view/165>. doi: https://doi.org/10.35479/ijretina.2021.vol004.iss002.165.

Correspondence to:

Elluru Pandu Rangaiah,

District Head Quarters

Hospital(Government),

Chittoor, Chittoor District, India,

info@biomedresearchservices.com

\section{INTRODUCTION}

Pregnancy hypertension is the one of the cause of maternal morbidity and mortality. Hypertension complicates $5-10 \%$ of pregnants to form a deadly triad, hemorrhage, or heart disease. According to $\mathrm{WHO}$, hypertension disorders in pregnancy account for $14 \%$ of maternal deaths. ${ }^{1}$ Pregnancy hypertensive disorders, such as chronic hypertension with/without superimposed preeclampsia/eclampsia, HELLP syndrome, gestational hypertension, preeclampsia with/without severe features, or eclampsia may pose risk to the mother and the foetus during pregnancy. ${ }^{2,3}$ 
Pregnancy hypertension usually appears after the 20th week of pregnancy. Multiple organs may be involved in $\mathrm{PIH}$, as well as hepatic dysfunction and platelet abnormalities. ${ }^{4} \quad$ Headache, drowsiness, seizures, hemiplegia, and coma were all symptoms of neurological involvement. Visual disturbances are a rare presenting symptom. ${ }^{5}$ Pregnancy-induced hypertension results in vision-threatening illnesses like central retinal artery occlusion, central serous retinopathy, secondary optic atrophy, retinal detachment, macular tear, choroidal ischemia, central retinal vein occlusion, and haemorrhage. ${ }^{6}$ The most common retinal change observed was arteriole narrowing.

Several retrospective studies have been published, ${ }^{7,8}$ there were not mentioned fundus changes. There was a scarcity of data on the occurrence of fundus alterations in $\mathrm{PIH}$ in the literature. The current study was carried out to determine the prevalence of retinal changes in pregnancy-induced hypertension, as well as the association between the retinal changes and blood pressure and the severity of hypertension.

\section{METHOD}

This hospital-based retrospective observational study collected data from 0101-2016 to 30-07-2020 for four years. Data were collected from medical records of 100 pregnant with pregnancy-induced hypertension, those who visit regularly for treatment to the district government hospital. The patients' ages, gravida, and para were recorded. Pregnant women who have recently developed hypertension in the 28th week of pregnancy with proteinuria visited at the department of obstetrics \& gynecology were included for the complete ophthalmological evaluation at the Department of Ophthalmology.

All pregnant women had their blood pressure taken. All referred pregnant from the obstetrics \& gynecology department underwent detailed ophthalmic examinations such as visual acuity test, complete slit-lamp examination of the anterior and posterior segments, and fundus picture of all eyes. The patient's retina was examined by the senior general ophthalmologist, who also trained in vitreoretinal services. To rule out any additional co-morbidities, a systemic examination was performed.

Data Analysis: The statistical analysis was carried out with the help of a statistical package for social sciences software version 16.0.(SPSS Inc., Chicago, IL, USA). The chisquare test was used to analyse all categorical data. The fundus findings and parity were compared and investigated. Fisher's exact test to assess the association. A ' $p$ ' value $<0.01$ was considered statistically significant.

\section{RESULT}

A total of 100 pregnant women were included, with 60 being between the ages of 21 and 26 years, 21 being between the ages of 26 and 30 years, 11 being between the ages of 20 and 30, and the rest being older than 30 years. The highest number of PIH cases $(n=81)$ were recorded in 21-30 years age group, followed by $11 \%$ in 20 years age group, and $8 \%$ in $>31$ years age group.

60 percent of primigravida instances and 40 percent in multigravida cases were identified. There was no association seen between fundus findings and the parity.

During admission, $67 \%$ of $\mathrm{PIH}$ cases had more than 32 weeks gestational age. There were $23 \mathrm{PIH}$ cases with 29-32 weeks gestational age, 7 with 25-28 weeks gestational age, and 3 cases with 25 weeks gestational age. Fifty-four patients have mild preeclampsia $(D B P<110 \mathrm{~mm} \mathrm{Hg}), 40$ have severe preeclampsia $(D B P \geq 110 \mathrm{~mm} \mathrm{Hg})$, and six have hypertension with seizures (Eclampsia).

41 cases had normal fundus, and 59 cases had abnormal fundus findings and the retinal changes in total $59 \%$ cases. 


\section{RESEARCH ARTICLE}

Of the 62 primigravidas, 23 (37.1\%) had normal fundus, and 39 (62.9\%) cases had abnormal fundus. 18 (47.3\%) cases of the 38 multigravidas had normal fundus, and 20 (52.6\%) cases had abnormal fundus. The majority of patients (41\%) had normal fundus or grade-1 hypertensive retinopathy (24\%). The majority of patients (41\%) had normal fundus or grade 1 hypertensive retinopathy (24\% ). 22\% cases had grade-2 hypertensive retinopathy, $6 \%$ cases had grade-3, and $2 \%$ had grade-4 hypertensive retinopathy. Another $2 \%$ of the pregnants were affected with macular edoema. Only $3 \%$ of the patients studied had central serous retina. Hypertensive retinopathy was found in $54 \%$ of the cases studied. As a result, hypertensive retinopathy is the most commonly observed symptom of $\mathrm{PIH}($ Table 1$)$.

Table 1. Grouping of fundus changes according to parity

\begin{tabular}{|c|c|c|c|c|c|c|}
\hline \multirow{3}{*}{ Fundus finding } & \multicolumn{6}{|c|}{ Gravida } \\
\hline & \multicolumn{2}{|c|}{ Primigravida } & \multicolumn{2}{|c|}{$\begin{array}{l}\text { Multi } \\
\text { gravida }\end{array}$} & \multicolumn{2}{|c|}{ Total } \\
\hline & $\mathrm{N}$ & $\%$ & $\mathrm{~N}$ & $\%$ & $\mathrm{~N}$ & $\%$ \\
\hline Normal Fundus & 23 & $37.1 \%$ & 18 & $47.4 \%$ & 41 & $41.0 \%$ \\
\hline Grade-1 HTN Retinopathy & 14 & $22.6 \%$ & 10 & $26.3 \%$ & 24 & $24.0 \%$ \\
\hline Grade-2 HTN Retinopathy & 16 & $25.8 \%$ & 6 & $15.8 \%$ & 22 & $22.0 \%$ \\
\hline Grade-3 HTN Retinopathy & 3 & $4.8 \%$ & 3 & $7.9 \%$ & 6 & $6.0 \%$ \\
\hline Grade-4 HTN Retinopathy & 2 & $3.2 \%$ & 0 & $.0 \%$ & 2 & $2.0 \%$ \\
\hline Central serous retinopathy & 3 & $4.8 \%$ & 0 & $.0 \%$ & 3 & $3.0 \%$ \\
\hline Macular edema & 1 & $1.6 \%$ & 1 & $2.6 \%$ & 2 & $2.0 \%$ \\
\hline Total & 62 & $100.0 \%$ & 38 & $100.0 \%$ & 100 & $100.0 \%$ \\
\hline
\end{tabular}

Fisher's exact test, $\mathrm{p}=0.565$.

A total of 54 patients were diagnosed with hypertensive retinopathy, with $59 \%$ having retinal changes. $44.4 \%$ of $\mathrm{PIH}$ patients had grade 1 hypertensive retinopathy with retinal arteriole narrowing. Changes in grade 2 account for $40.7 \%, 11.1 \%$ in grade-3, and $3.7 \%$ in grade- 4 . (Table 2).

Table 2. Complaint Status

\begin{tabular}{lllllllllll}
\hline Fundus finding & \multicolumn{1}{l}{ Complaint } \\
& \multicolumn{1}{l}{ Nil } & \multicolumn{1}{l}{ Headache } & \multicolumn{2}{l}{ Blurred Vision } & \multicolumn{2}{l}{ Loss of Vision } & \multicolumn{2}{l}{ Total } \\
\cline { 2 - 13 } & $\mathrm{N}$ & $\%$ & $\mathrm{~N}$ & $\%$ & $\mathrm{~N}$ & $\%$ & $\mathrm{~N}$ & $\%$ & $\mathrm{~N}$ & $\%$ \\
\hline Normal finding & 4 & $36.4 \%$ & 22 & $36.7 \%$ & 16 & $55.17 \%$ & 0 & $0 \%$ & 41 & $41.0 \%$ \\
\hline Grade-1 HTN Retinopathy & 4 & $36.4 \%$ & 14 & $23.3 \%$ & 6 & $20.68 \%$ & 0 & $0 \%$ & 24 & $24.0 \%$ \\
\hline Grade-2 HTN Retinopathy & 2 & $18.2 \%$ & 15 & $25.0 \%$ & 5 & $17.24 \%$ & 0 & $0 \%$ & 22 & $22.0 \%$ \\
\hline Grade-3 HTN Retinopathy & 0 & $.0 \%$ & 4 & $6.7 \%$ & 2 & $6.9 \%$ & 0 & $0 \%$ & 6 & $6.0 \%$ \\
\hline Grade-4 HTN Retinopathy & 0 & $0.0 \%$ & 2 & $3.3 \%$ & 0 & $0 \%$ & 0 & $0 \%$ & 2 & $2.0 \%$ \\
\hline Central serous retinopathy & 1 & $9.1 \%$ & 2 & $3.3 \%$ & 0 & $0 \%$ & 0 & $0 \%$ & 3 & $3.0 \%$ \\
\hline Macular edema & 0 & $.0 \%$ & 1 & $1.7 \%$ & 0 & $0 \%$ & 0 & $0 \%$ & 2 & $2.0 \%$ \\
\hline Total & 11 & 100.0 & 60 & 100.0 & 29 & 100.0 & 0 & $0 \%$ & 100 & $100.0 \%$ \\
\hline
\end{tabular}


Table 3: Organizing the fundus findings by age group

\begin{tabular}{|c|c|c|c|c|c|c|c|c|c|c|c|c|}
\hline \multirow[t]{3}{*}{ Fundus finding } & \multicolumn{12}{|c|}{ Age group (years) } \\
\hline & \multicolumn{2}{|c|}{$<=20$ yrs } & \multicolumn{2}{|c|}{$21-25$ yrs } & \multicolumn{2}{|c|}{$26-30$ yrs } & \multicolumn{2}{|c|}{$31-35$ yrs } & \multicolumn{2}{|c|}{$>35$ yrs } & \multicolumn{2}{|c|}{ Total } \\
\hline & $\mathrm{N}$ & $\%$ & $\mathrm{~N}$ & $\%$ & $\mathrm{~N}$ & $\%$ & $\mathrm{~N}$ & $\%$ & $\mathrm{~N}$ & $\%$ & $\mathrm{~N}$ & $\%$ \\
\hline Normal finding & 4 & $36.4 \%$ & 22 & $36.7 \%$ & 13 & $61.9 \%$ & 1 & $16.7 \%$ & 1 & 50.0 & 41 & $41.0 \%$ \\
\hline Grade-1 HTN Retinopathy & 4 & $36.4 \%$ & 14 & $23.3 \%$ & 3 & $14.3 \%$ & 3 & $50.0 \%$ & 0 & $.0 \%$ & 24 & $24.0 \%$ \\
\hline Grade-2 HTN Retinopathy & 2 & $18.2 \%$ & 15 & $25.0 \%$ & 3 & $14.3 \%$ & 2 & $33.3 \%$ & 0 & $.0 \%$ & 22 & $22.0 \%$ \\
\hline Grade-3 HTN Retinopathy & 0 & $.0 \%$ & 4 & $6.7 \%$ & 2 & $9.5 \%$ & 0 & $.0 \%$ & 0 & $.0 \%$ & 6 & $6.0 \%$ \\
\hline Grade-4 HTN Retinopathy & 0 & $.0 \%$ & 2 & $3.3 \%$ & 0 & $.0 \%$ & 0 & $.0 \%$ & 0 & $.0 \%$ & 2 & $2.0 \%$ \\
\hline Central serous retinopathy & 1 & $9.1 \%$ & 2 & $3.3 \%$ & 0 & $.0 \%$ & 0 & $.0 \%$ & 0 & $.0 \%$ & 3 & $3.0 \%$ \\
\hline Macular edema & 0 & $.0 \%$ & 1 & $1.7 \%$ & 0 & $.0 \%$ & 0 & $.0 \%$ & 1 & $50.0 \%$ & 2 & $2.0 \%$ \\
\hline Total & 11 & $100.0 \%$ & 60 & $100.0 \%$ & 21 & 100.0 & 6 & $100.0 \%$ & 2 & 100.0 & 100 & 100.0 \\
\hline
\end{tabular}

$\mathrm{PIH}$ was observed in primigravidas more frequently than in multigravidas. However, the fundus findings did not correlate with parity. There was no association between the Fundus findings and parity(Fisher's exact test, $\mathrm{P}=0.565$ )(Table 3 ). There is no association between the patient's age and fundus findings (Fisher's exact test, $p=0.502$ ) (Table 4).

Table 4: The relationship between fundus findings and the severity of hypertension

\begin{tabular}{|c|c|c|c|c|c|c|c|c|}
\hline \multirow{3}{*}{ Fundus finding } & \multicolumn{8}{|c|}{ type of PIH } \\
\hline & \multicolumn{2}{|c|}{$\begin{array}{l}\text { Mild HTN } \\
(\mathrm{DBP}<100)\end{array}$} & \multicolumn{2}{|c|}{$\begin{array}{l}\text { Severe HTN } \\
(\mathrm{DBP}>=100)\end{array}$} & \multicolumn{2}{|c|}{ Eclampsia } & \multicolumn{2}{|c|}{ Total } \\
\hline & $\mathrm{N}$ & $\%$ & $\mathrm{~N}$ & $\%$ & $\mathrm{~N}$ & $\%$ & $\mathrm{~N}$ & $\%$ \\
\hline Normal & 30 & $55.6 \%$ & 11 & $27.5 \%$ & 0 & $.0 \%$ & 41 & $41.0 \%$ \\
\hline Grade-1 HTN Retinopathy & 15 & $27.8 \%$ & 7 & $17.5 \%$ & 2 & $33.3 \%$ & 24 & $24.0 \%$ \\
\hline Grade-2 HTN Retinopathy & 9 & $16.7 \%$ & 13 & $32.5 \%$ & 0 & $.0 \%$ & 22 & $22.0 \%$ \\
\hline Grade-3 HTN Retinopathy & 0 & $.0 \%$ & 6 & $15.0 \%$ & 0 & $.0 \%$ & 6 & $6.0 \%$ \\
\hline Grade-4 HTN Retinopathy & 0 & $.0 \%$ & 0 & $.0 \%$ & 2 & $33.3 \%$ & 2 & $2.0 \%$ \\
\hline Central serous retinopathy & 0 & $.0 \%$ & 2 & $5.0 \%$ & 1 & $16.7 \%$ & 3 & $3.0 \%$ \\
\hline Macular edema & 0 & $.0 \%$ & 1 & $2.5 \%$ & 1 & $16.7 \%$ & 2 & $2.0 \%$ \\
\hline Total & 54 & $100.0 \%$ & 40 & $100.0 \%$ & 6 & $\begin{array}{l}100.0 \\
\%\end{array}$ & 100 & $100.0 \%$ \\
\hline
\end{tabular}

All 100 cases had fundus changes, which were correlated with hypertension severity, and two variables had a strong association ( $p=0.001$, Fisher's exact test). As the severity of hypertension increased, so did the likelihood of abnormal fundus findings. The fundus findings were found to have a positive correlation with the hypertension severity. (Table 5). 
Table 5. Status of Visual Acuity (BE)

\begin{tabular}{|c|c|c|c|c|c|c|c|c|}
\hline \multirow[b]{3}{*}{ Fundus finding } & \multicolumn{8}{|c|}{ type of PIH } \\
\hline & \multicolumn{2}{|l|}{$6 \backslash 6$} & \multicolumn{2}{|c|}{$6 \backslash 12$} & \multicolumn{2}{|c|}{ CFCF } & \multicolumn{2}{|c|}{ Total } \\
\hline & $\mathrm{N}$ & $\%$ & $\mathrm{~N}$ & $\%$ & $\mathrm{~N}$ & $\%$ & $\mathrm{~N}$ & $\%$ \\
\hline Normal findings & 41 & $52.56 \%$ & 0 & $0 \%$ & 0 & $.0 \%$ & 41 & $41.0 \%$ \\
\hline Grade-1 HTN Retinopathy & 22 & 28.2 & 2 & $11.11 \%$ & 0 & $0 \%$ & 24 & $24.0 \%$ \\
\hline Grade-2 HTN Retinopathy & 15 & $19.23 \%$ & 7 & $38.89 \%$ & 0 & $.0 \%$ & 22 & $22.0 \%$ \\
\hline Grade-3 HTN Retinopathy & 0 & $.0 \%$ & 6 & $33.33 \%$ & 0 & $.0 \%$ & 6 & $6.0 \%$ \\
\hline Grade-4 HTN Retinopathy & 0 & $0 \%$ & 0 & $0 \%$ & 2 & $33.3 \%$ & 2 & $2.0 \%$ \\
\hline Central serous retinopathy & 0 & $.0 \%$ & 2 & $11.11 \%$ & 1 & $16.7 \%$ & 3 & $3.0 \%$ \\
\hline Macular edema & 0 & $0 \%$ & 1 & $5.5 \%$ & 1 & $16.7 \%$ & 2 & $2.0 \%$ \\
\hline Total & 78 & $100.0 \%$ & 18 & $100.0 \%$ & 4 & $\begin{array}{l}100.0 \\
\%\end{array}$ & 100 & $100.0 \%$ \\
\hline
\end{tabular}

\section{DISCUSSION}

The retina is a unique location where the vasculature of the human body can be seen directly with an ophthalmoscope. Hence, a change in retinal arterioles indicates the similar state of placenta, provides the reasonable idea for placental circulation and fetus health. If $\mathrm{PIH}$ is detected early, maternal and fetal complications can be avoided.9,10 The pathological changes are related to vascular endothelial dysfunction and its consequences (generalized vasospasm and capillary leak). Vasospastic manifestations are reversible, and the retinal vessels return to normal soon after birth. ${ }^{4,11}$

The pregnant's mean age was $25.2 \pm 5.89$ years in the present study. In a study by Jaeffe and Schatz, it was 28 years. ${ }^{4}$ In the present study, age was does not shown association with retinal changes $(P>0.05)$. This was consistent with study by Reddy et al. ${ }^{11}$ In the present study, $62 \%$ (62) were primigravidae and $38 \%$ (38) were multigravidae. In an Indian study, K Nandha et al. discovered that 67 percent of $\mathrm{PIH}$ cases were primigravidas. ${ }^{12}$ In our study, gravida was not associated with retinopathy changes, which is consistent with the findings of Reddy et al.

In the present study, $54 \%$ of cases had mild hypertension < $110 \mathrm{~mm} \mathrm{Hg.} 40 \%$ of patients had severe hypertension $\geq 110 \mathrm{~mm} \mathrm{Hg}$, and $6 \%$ had hypertension with seizures (eclampsia). In a study of 300 cases of $\mathrm{PIH}$, Bakhda RN et al. reported 182 cases had mild preeclampsia, 76 cases had severe preeclampsia, and 42 cases had eclampsia. ${ }^{7}$ Bhandari et al. reported $32 \%$ of patients had mild pre-eclampsia, 50\% had severe pre-eclampsia, and $18 \%$ cases had eclampsia.

In the current study, 59\%cases had retinal changes. Tadin et al. reported $45 \%$ of retinal changes. ${ }^{13}$

In the current study, hypertensive retinopathy was the most common finding in $54 \%$ of patients $[24 \%$ grade $1,22 \%$ of grade 2 hypertensive retinopathy], there were three cases had central serous retinopathy and two cases had macular edema grade-4 retinopathy (macular edema occurred concurrently with hypertensive retinopathy). Both the cases with grade 4 retinopathy had blood pressure $160 / 110 \mathrm{~mm} \mathrm{Hg}$ and the fundus showed no disc edema. The most common fundus finding was arteriole narrowing (45.7\%). Topical antiinflammatory medication was given to patients with macular edoema and central serous retinopathy. Bhandari $A J$ et al., study reported exudative retinal detachment occurs in $7 \%$ of 
$\mathrm{PIH}$ cases and $12 \%$ cases had macular edema. ${ }^{8}$

Reddy et al., recorded retinal changes in 53.4\% of preeclampsia, and $71.2 \%$ of eclampsia. Jaffe and Schatz, as well as Reddy et al., have both confirmed the absence of hemorrhages and exudates. This is due to proper antenatal care and early detection of $\mathrm{PIH}$ cases, which prevents them from progressing to Grade 3 hypertensive retinopathy.

The current study found a positive correlation between the fundus findings and hypertension severity. Similar to previous studies, the severity of $\mathrm{PIH}$ was significantly $(\mathrm{P}=0.004)$ associated with retinopathy. ${ }^{14-18}$ Similarly, Tadin et al., study identified that the degree of retinopathy was proportional to preeclampsia severity. According to them, the presence of hypertensive retinopathy is one of the prognostic factor for the severity of preeclampsia.

\section{CONCLUSION}

Retinal changes are the indicator of hypertension severity. In $\mathrm{PIH}$ patients, grade- 1 and grade- 2 hypertensive retinopathy is the common. The presence of disc edema, macular edema, or retinal detachment was an indication that the procedure should be terminated. The retinal changes resolve shortly after the pregnancy is terminated. If the retinal changes persist, a history of chronic hypertension must be ruled out. Pregnant hypertensive mothers should be followed up on for their babies, who will be screened for Retinopathy of Prematurity, and early detection of toxaemic retinopathy may help obstetricians to manage the mother and fetus. Patients must be followed up even after the pregnancy is terminated until the retinal changes resolve.

\section{REFERENCES}

1. Cunningham FG, Lenovo KJ, Bloom SL, Dashe JS, Hoffman BL, Catherine YS. Williams Obstetrics. 25th ed. New York, NY: Mc Graw Hill Companies; 2018:710-754.

2. Say L, Chou D, Gemmill A, Moller AB, Daniels J, Temmerman $\mathrm{M}$, et al. Global causes of maternal death: a WHO systematic analysis. Lancet Glob Health. 2014;2(6):323-33.

3. Roberts JM, August PA, Bakris G, Barton JR, Bernstein $I M$, Druzin $M$, et al. Hypertension in pregnancy. Report of the American college of obstetricians and gynecologists' task force on hypertension in pregnancy. Obstet Gynecol. 2013;122(5):1122-31.

4. Jaffe $G$, Schatz $H$. Ocular manifestations of preeclampsia. Am J Opthalmol 1987;103(3 Pt 1):309315.

5. Bharathi NR, Raju NRS, Prasad PK, et al. Fundus changes in pregnancy induced hypertension: a clinical study. Journal of Evolution of Medical and Dental Sciences 2015;4(9):1552-1562.

6. Javedekar SD, Javadekar DP, Joshi K, et al. Fundoscopic changes in pregnant mother with hypertension complicating pregnancy and various parameters of foetus. International Journal of Recent Trends in Science and Technology 2013;7(3):110113.

7. Bakhda RN. Clinical study of fundus findings in pregnancy induced hypertension. J Family Med Prim Care 2016;5:424-9

8. Bhandari AJ, Bangal SV, Gogri PY. Ocular fundus changes in pre-eclampsia and eclampsia in a rural set-up. J Clin Ophthalmol Res 2015;3:139-42 9. Kurdoglu $Z$, Kurdoglu $M$, Gülçin Ay $E$, et al. Retinal findings in cases of preeclampsia. Perinatal Journal 2011;19(2):60-63.

10. Richard RO. Pregnancy induced hypertension (preeclampsia-ecclampsia). In: Schachat AP, Murphy RB, editors. Retina. $2^{\text {nd }}$ ed. St. Louis: Mosby; 1994. p. 1405-12

11. Reddy SC, Naliah S, Rani S. Fundus changes in pregnancy induced hypertension. Int J Ophthalmol 2012;5(6):694-697. 
12. Nandha KV, Swamyraj SV, Hassan KM, et al. Fundus changes in pregnancy induced hypertension in a university hospital of South India. J. Evid. Based Med. Healthc. 2020; 7(8), 404-408).

13. Tadin I, Bojić L, Mimica $M$, et al. Hypertensive retinopathy and preeclampsia. Coll Antropol 2001;25 Suppl:77-81.

14. Raidi AR, Nik-Ahmad-Zuky NL, Bakiah $\mathrm{S}$, et al. Hypertensive retinopathy and visual outcome in hypertensive disorders in pregnancy. Med J Malaysia 2011;66(1):42-47.

15. Karki P, Malla P, Das H, Uprety DK. Association between pregnancy-induced hypertensive fundus changes and fetal outcomes. Nepal J Ophthalmol 2010;2:26-30,
16. Sunness JS. The pregnant woman's eye. Surv Ophthalmol 1988;32:219-38,

17. Ober RR. Pregnancy induced hypertension. In: Ryan SJ, editor. Retina. Toronto: Mosby Publications; 1994. p. 441-7,

18. Shah AP, Lune AA, Magdum RM, Deshpande $H$, Shah AP, Bhavsar D. Retinal changes in pregnancy-induced hypertension. Med J DY Patil Univ 2015;8:304-7.

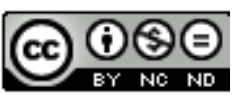

This work licensed under Creative Commons Attribution 